\title{
Omkring den hamborgske Hydra
}

Indtil Carl von Linné satte tingene $i$ dyreriget på plads i sit banebrydende vark Systema Naturæ fra 1735, kunne charlataner let slippe af sted med fremvisning af udstoppede monstre, som efter sigende skulle have vandret levende rundt - engang...

\section{af bibliotekskonsulent Torsten Schlichtkrull, Det Kongelige Bibliotek}

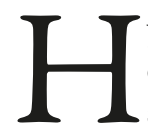

ydra er et af de klassiske fabeldyr; den fremstilles som regel som en mangehovedet slange. Antallet af hoveder varierer, men vores Hydra, den hamborgske, har syv.

$\mathrm{Om} \mathrm{Hydra}^{1}$ (vand-uhyret) fortælles det, at den var umådeligt giftig, og at den var svær at komme til livs. Først når det sidste hoved, det udødelige, var hugget af, havde man gjort kål på uhyret. Men når man huggede et hoved af, voksede der to nye ud i stedet, og det gjorde ikke sagen lettere. Den Hydra, der omtales i den grxske mytologi, boede i sumpene ved Lerna syd for Argos på Peloponnes, og kaldes derfor den lernæiske Hydra. Den voldte befolkningen stor skade, og Herakles blev sendt ud for at dræbe den. Det lykkedes, men kun fordi han fik hjælp af sin ledsager til at svide halsene med brændende grene, så der ikke hele tiden voksede nye hoveder ud. Hydra havde ikke sine uhyggelige egenskaber fra fremmede. Faderen var urtidsuhyret Tyfon, som har lagt navn til de tropiske hvirvelstorme; moderen var Echidna (kvinde foroven og slange forneden), om hvem det stort set kun fortælles, at hun ud over Hydra var mor til bæster

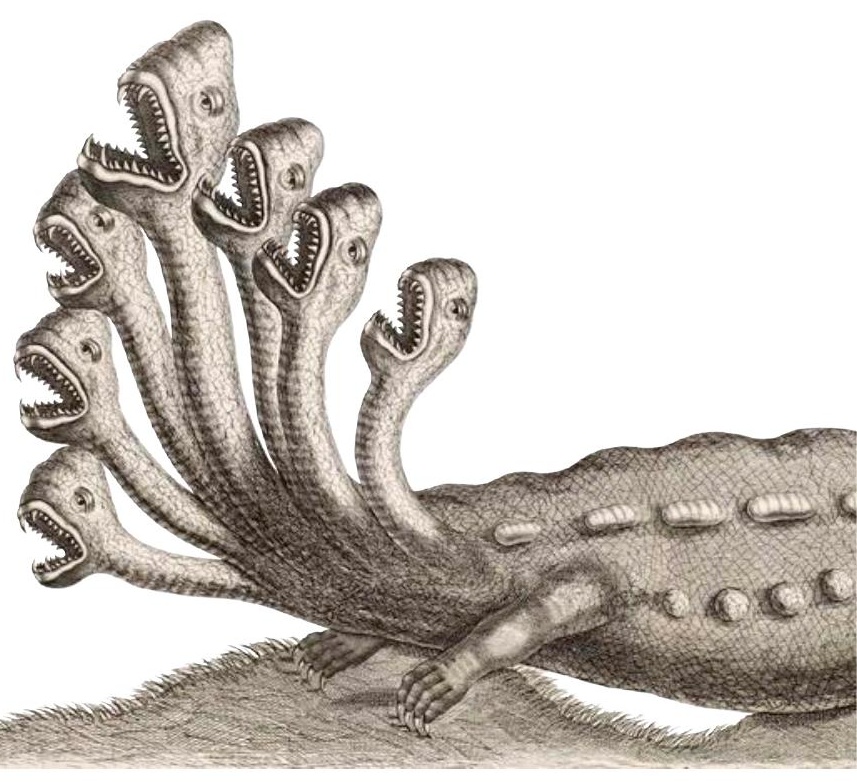

som f.eks. Kerberos, der vogtede indgangen til - og udgangen fra - dødsriget, og Skylla, som Odysseus kom faretruende nær for at undgå Charybdis' malstrøm. En ganske anden forklaring på Hydraen er, at der kan være tale om en stor blæksprutte, hvor hver arm er suppleret med et hoved. Der findes et billede på en græsk amfora, hvor man tydeligt kan se, hvad der grangiveligt ligner sugekopperne på blækspruttens arme.

Her fortæller vi om den hamborgske Hydra, som naturligvis var et falsum. Ikke desto mindre bidrog den mere eller mindre indirekte til, at en ung, velhavende dansker blev hjulpet af med en hoben penge, en viceadmiral blev hjulpet af med livet, og en ung, fremadstormende naturforsker kunne afsløre falskneriet. Alt sammen i første halvdel af 1700-tallet.

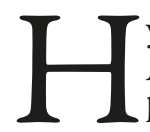
ydraen først: I 1734 udgav Albertus Seba (1665-1736), en hollandsk apoteker, zoolog og samler, første bind af en tesaurus (dvs. en systematisk fortegnelse) over dyr og planter. ${ }^{2}$ Teksten var på latin med en paralleltekst på enten hollandsk eller fransk. 


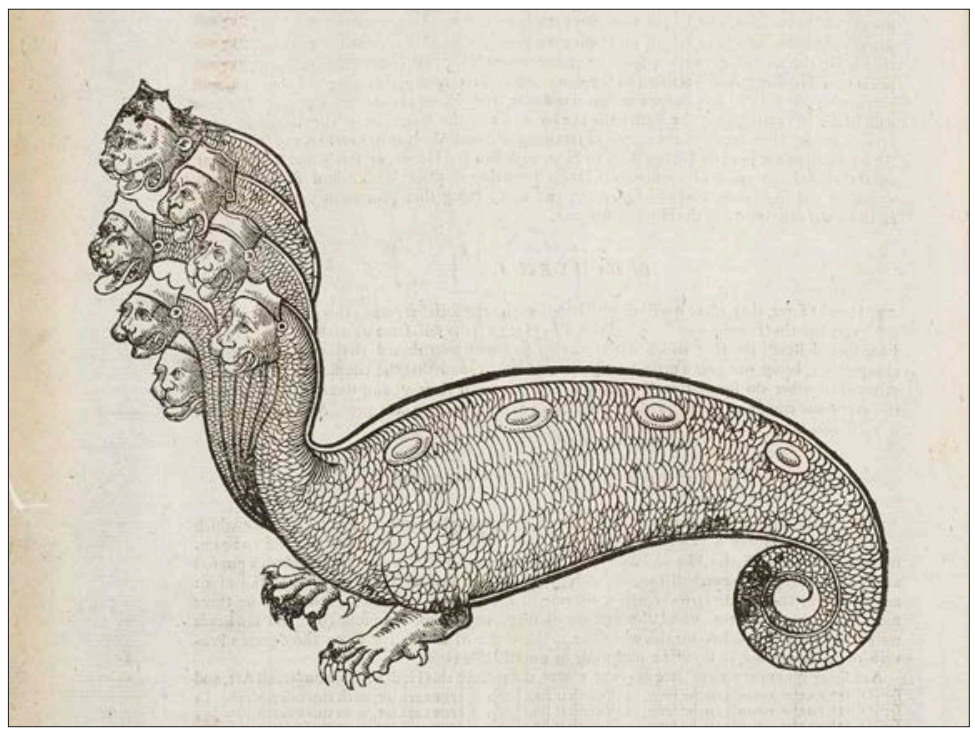

Conrad Gesners Hydra, gengivet efter Topsell.

Begyndelsen af Topsells tekst lyser: "Of the

HYDRA, supposed to be killed by Hercules. The Poets do sain, that neer to the Fountain Anymona, there grew a Plantain, under which was bred a Hydra which had seven heads..." Edward Topsel: The history of four-footed beasts and serpents : collected out of the writings of Conradus Gesner and other authors ..., London, 1658.

I Det Kongelige Biblioteks eksemplar er parallelteksten på hollandsk. Der kom i alt fire bind, de to sidste efter Sebas død. I bind et viser han den hamborgske Hydra ${ }^{3}$ og fortæller, at han i 1720 havde fået en tegning af dyret af en fremmed, som havde set dyret med egne øjne, men at han tvivlede på, om dyret var ægte. Året efter havde Seba igen af to forskellige troværdige, navngivne personer fået fortalt om den hamborgske Hydra, og denne gang forsikrede Sebas hjemmelsmænd ham om, at uhyret ikke var et kunstprodukt, men "het natuurlyk, en niet naar de kunst gemaakt was”. Seba så aldrig selv uhyret, men han var ikke længere i tvivl om eksistensen, og han bestilte derfor en tegning - den tegning, han publicerede. Seba fortalte også, at Hydraen var til salg for 10.000 floriner, en ganske stor sum. Der var faktisk et udstoppet væsen af den karakter i Hamborg, og det var til salg; efter sigende skulle den danske konge uden held have budt 30.000 Thaler for den. ${ }^{4}$

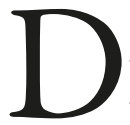
et var ikke første gang, en Hydra var blevet vist i de zoologiske værker. Conrad Gesner (151665) havde en med i sit store værk, Historia Animalium, Ulisse Aldrovandi (15221605) havde Gesners figur plus en til i sit værk om slanger, og Edward Topsell (ca. 1572-1625), der baserer sig på Gesner, gentog Gesners figur, så selv om der blev ytret tvivl om eksistensen af væsenet Gesner placerede Hydra i gruppen af tvivlsomme dyr - så "overlevede" Hydra i litteraturen i nogle hundrede år. Den hamborgske Hydra stammede fra en kirke i Prag, hvorfra den var blevet taget som krigsbytte i år 1600, og sidenhen var den kommet til Hamborg, hvor den var i 1720, da Seba første gang hørte om den.

Netop i 1720 var den unge Abraham Lehn $^{5}$ (1702-1757) på vej ud på den dannelsesrejse, der på 18 måneder skulle føre ham vidt omkring i Europa. Lehn var velhavende, meget velhavende. Allerede da Abraham var otte år, var faderen død 
Ulisse Aldrovandi (15221605) var en af tidens mange larde. Han skrev adskillige boger inden for det, vi i dag kalder zoologi-ogtilgrensende fag, således også en Historia monstrorum, som handlede om monstre, spandende fra menneskelige misfostre over fabeldyr til astronomiske fanomener saisom kometer. Flere af hans boger blev forst udgiver efter hans dod. Ulisse Aldrovandi: Serpentum et Draconum historiæ libri duo, Bononia, 1640.

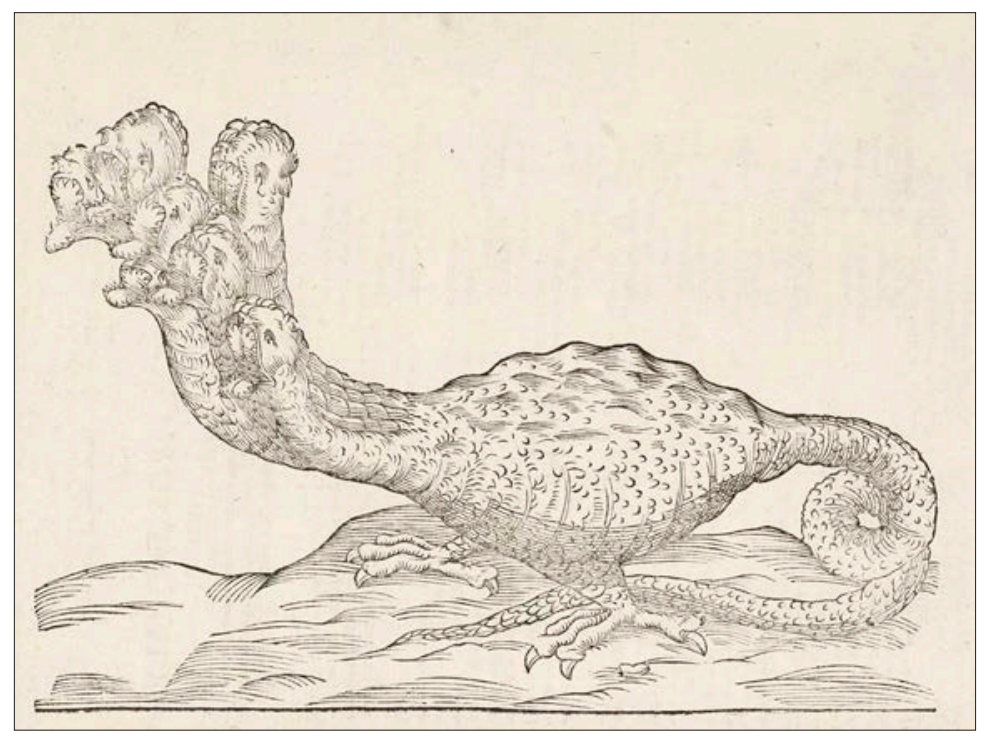

fra sine tre børn. Faderen, der også hed Abraham, havde tjent godt som vinhandler, købmand og skibsreder; han efterlod sig ca. 400.000 Rdl. Allerede fem år senere døde den ene bror, og nu stod den umyndige Abraham Lehn med en formue på $211.000 \mathrm{Rdl}$., i dag formentlig et trecifret millionbeløb. Vel ankommen til Hamborg hørte 18-årige Lehn, at der fandtes en syvhovedet slange i byen, og den ville han gerne se. Slangen blev brugt af sin ejer, oberst Staël von Holstein, til at lokke ubefæstede sjæle til sit spillebord. Den unge Abraham Lehn lod sig bondefange, kørte til et ukendt sted, fik ikke set uhyret, men blev til gengæld hjulpet af med en del penge; hvor mange melder historien intet sikkert om. Obersten, Jacob Axel Stäel von Holstein (1680-1730), havde været i svensk tjeneste, og danske og svenske beretninger er ikke helt enige om, hvorvidt han spillede falsk eller ej.

På rejsen begyndte Lehn - meget sympatisk - at samle bøger, og da han kom hjem i 1721 satte han sine penge i godser, i stedet for at slå sig på handel som faderen havde ønsket. Han fik forholdsvis hurtigt samlet et fortrinligt bibliotek. Københavns Universitetsbibliotek gik som bekendt til grunde ved Københavns brand i 1728, og i opbygningsfasen solgte Abraham Lehn 13-1400 bind til Universitetet for blot 2.400 Rdl. Det var et rigtig godt køb for Universitetsbiblioteket; de to forhandlere, Hans Gram og Chr. Worm, erklærede, at hvis Universitetet ikke ville købe bøgerne for den foreslåede pris, så ville de gerne selv. Købet betegnes som et af de vigtigste i bibliotekets opbygningsfase. ${ }^{6}$

Abraham Lehn havde en bekendt, Peter Wessel Tordenskiold (1690-1720). Tordenskiold boede i den Lehnske Gaard ${ }^{7}$ på Christianshavn (nu Strandgade 6), men behøver ellers ikke nogen nærmere præsentation her. Kort tid efter at Lehn havde forladt Hamborg, kom Tordenskiold $^{8}$ selv dertil. Her hørte han om, hvordan det var gået Lehn, og det forargede ham. Fra Hamborg tog han til Hannover, 
og ved et middagsselskab, hvor oberst Staël von Holstein var til stede, udtalte han sig i skarpe vendinger om det.

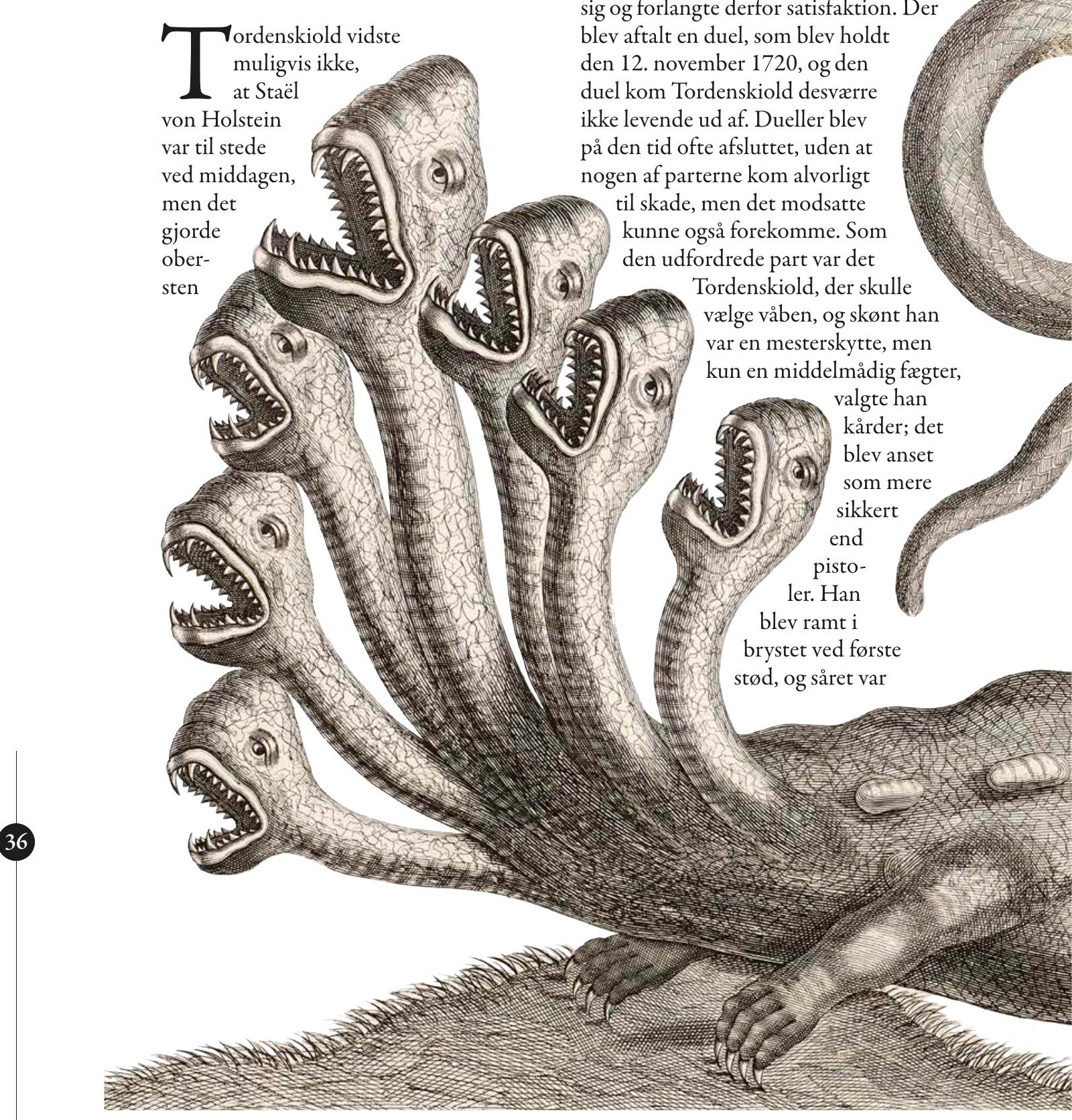

ham selv opmærksom på, og det kom til et håndgemæng, hvor obersten fik en dragt prygl. Det kunne han ikke lade sidde på sig og forlangte derfor satisfaktion. Der blev aftalt en duel, som blev holdt den 12. november 1720, og den duel kom Tordenskiold desværre ikke levende ud af. Dueller blev på den tid ofte afsluttet, uden at nogen af parterne kom alvorligt odsatte kunne også forekomme. Som den udfordrede part var det

Tordenskiold, der skulle vælge våben, og skønt han var en mesterskytte, men kun en middelmådig fægter, 
dødeligt. Det er ikke klarlagt præcis, om stødet skulle dræbe, eller om det blev ekstra kraftigt, fordi Tordenskiold samtidig gjorde et udfald mod sin modstander, så selv om Staël von Holstein uden al tvivl var en skidt fyr, kan det ikke bevises, at der var tale om et mord.

15 år senere kom en ung, fremadstormende svensk læge og naturforsker gennem Hamborg; han skulle til

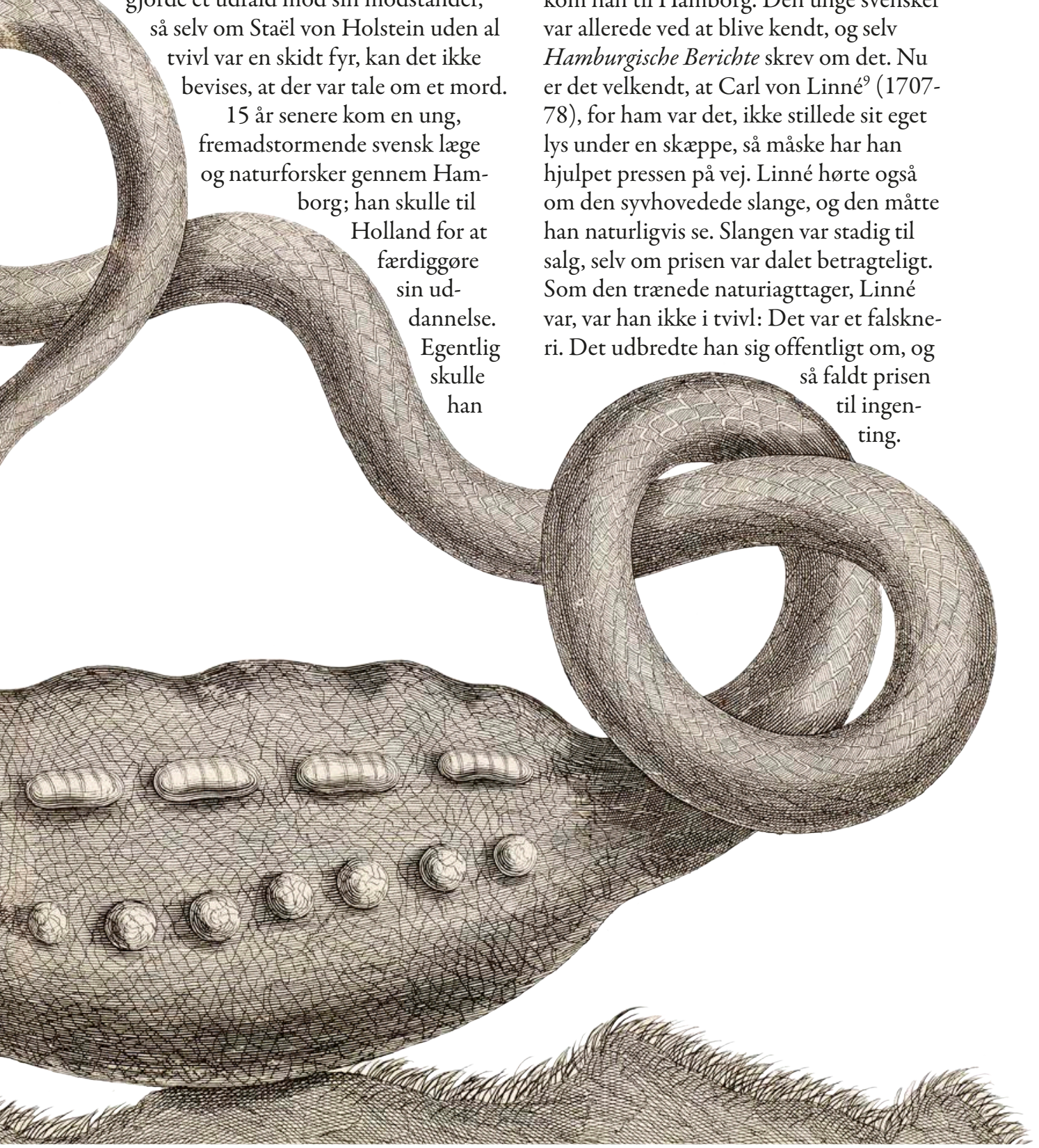

have sejlet direkte fra Helsingør til Holland, men vinden var ikke gunstig, hvorfor han valgte at tage en anden vej, og så kom han til Hamborg. Den unge svensker var allerede ved at blive kendt, og selv Hamburgische Berichte skrev om det. $\mathrm{Nu}$ er det velkendt, at Carl von Linné9 (170778), for ham var det, ikke stillede sit eget lys under en skæppe, så måske har han hjulpet pressen på vej. Linné hørte også om den syvhovedede slange, og den måtte han naturligvis se. Slangen var stadig til salg, selv om prisen var dalet betragteligt. Som den trænede naturiagttager, Linné var han ikke i tvivl: Det var et falsknealdt prisen 
Det var byens borgmester, der ejede slangen, og han blev ikke glad; Linné og hans følgesvend valgte derfor skyndsomst at forlade Hamborg.

I Holland, rejsens egentlige mål, udgav Linné senere samme år første udgave af sit hovedværk, Systema Nature. Den vakte straks opsigt og var med til at slå Linnés navn fast. Linné delte værket op i de tre kendte "riger", dyrerige, planterige og mineralrige, og hvert rige i flere taksonomiske niveauer. I dag er der flere riger, eksempelvis betragtes planter og svampe som to riger for sig. I forbindelse med dyreriget opførte Linné nogle "Paradoxa", absurditeter, hvor han skrev, hvad han mente om forskellige fabeldyr, og det fremgik klart, at han benægtede deres eksistens. Om Hydraen skrev han:

C En Hydra med slangekrop, to fødder, syv halse og ligeså mange hoveder, uden vinger, findes i Hamburg. Den har en vis lighed med den apokalyptiske hydra som beskrevet af Skt. Johannes, kap. 12 og 13. Den fremtræder i mange henseender som et rigtigt levende væsen,

\section{Noter}

1 Jean Anker og Svend Dahl: Fabeldyr og andre Fabelvesener i Fortid og Nutid, 1938, s. 75-80; Chr. Gorm Tortzen: Antik mytologi, 2004, s. 150f., 283, 293.

2 Albertus Seba: Locupletissimi rerum naturalium thesauri accurata descriptio, et iconibus artificiocissimis expressio per universam physices historiam, opus, cui in hoc rerum genere, nullum par exstitit, 4 bd., Amstelaedami 1734.

3 Ibid., tavle CII samt s. 158-60.

4 Wilfrid Blunt: The Compleat Naturalist. A Life of Linnaeus, London 1971, s. 90.

5 Sven Houmøller: Abraham Lehn og Bibliotekerne paa Berritzgaard og Oreby, 1952, s. $8 \mathrm{ff}$. men det er den ikke. Naturen er altid i overensstemmelse med sig selv, og den har aldrig frembragt flere hoveder på én krop på naturlig vis. Tænderne var af den vilde mår-families slags, og de er anderledes end krybdyrenes tænder, så det afslørede med al ønskelig tydelighed da jeg selv tog det i øjesyn, at der var tale om et menneskeskabt falskneri." 10

Og det var så det, ingen Hydra. Der er ingen tvivl om, at den Hydra, Linné så, er den samme, som er afbildet hos Seba, og at den samme Hydra selv havde bidraget til mulige falsknerier og til en søhelts død. Man må sige, at den fik efter fortjeneste.

\section{yo}

Gesners, Aldrovandis og Sebas Hydraer i bøgerne ser sandt at sige ikke særligt uhyggelige ud i dag, hvor man er anderledes vant. Vil man se en fremstilling af Herakles' kamp med Hydraen, hvor Hydra er fremstillet med en gru, som kan give børn mareridt, kan man tage til Helsingør: Her står Rudolph Tegners skulptur på ydermolen.

6 Palle Birkelund: "Universitetsbiblioteket 1729-1926”, i Københavns Universitet 1479-1979, red. Svend Ellehøj et al., bd. 4, 1979, s. 373.

7 Houmøller: Abraham Lehn og Bibliotekerne paa Berritzgaard og Oreby, s. $10 \mathrm{f}$.

8 Dan H. Andersen: Mandsmod og kongegunst - en biografi om Peter Wessel Tordenskiold, 2004, s. $306 \mathrm{ff}$.

9 Blunt: The Compleat Naturalist. A Life of Linnaeus, s. 87ff.

10 Torsten Schlichtkrull: Natursyn. Fra fabeldyr til systemer, 2007, s. 40. Oversættelse fra latin: Karen Skovgaard-Petersen. 